\title{
Influence of ZnO Nanoparticle Size and Concentration on the Polysulfone Membrane Performance
}

\author{
STEFAN CATALIN PINTILIE*, LAURENTIA GEANINA TIRON, IULIAN GABRIEL BIRSAN, DANIEL GANEA, STEFAN BALTA \\ Dunarea de J os University of Galati, 47 Domneascã Str., 800008 Galati, Romania
}

\begin{abstract}
The activity of using membrane technology has developed fast in the treatment of wastewater, drinking water and process water production. The main challenges in membrane filtration are fouling reduction, permeability increase and high efficiency in retention. The best example of membrane enhancement is increasing hydrophilicity. Nanoparticles have been proven that their presence in the membrane matrix increases the water affinity significantly. Although the zinc oxide nanoparticles have a positive effect over the membrane performance, the influence of zinc oxide $(\mathrm{ZnO})$ nanoparticle size has not been studied enough. Two sizes of nanoparticle of $\mathrm{ZnO}$ and three concentrations were used for the preparation of composite polysulfone ultrafiltration membranes. The effects of the $\mathrm{ZnO}$ nanoparticles in the membrane matrix on the permeation properties, flux stability and retention were tested. SEM, EDX, porosity and contact angle measurement were conducted in this article, also. The experimental results indicated that ZnO-PSf composite membranes exhibits significant differences in the membrane properties due to nanoparticle addition and regardless of their size it leads to an increase in hydrophilicity, flux, permeability, retention and porosity. Decreasing the nanoparticle size leads to an increase in membrane performance.
\end{abstract}

Keywords: Polysulfone (PSf) membranes, ZnO nanoparticles, Nanoparticle size

Membrane separation had earned a growth in popularity over the last twenty years and became one of the most promising treatment technologies so far [1].

Separation based membranes are applicable in many industries such as chemical [2, 3], food and pharmaceutical [4-6] industries, possessing important advantages such as no by-product production, low temperature process and an exceptional cost/efficiency ratio in comparison with the conventional treatment plants $[7,8]$.

Continuous research is conducted worldwide on improving the membrane performance and membrane processes [9-12]. Increasing the separation yield [9] and the membrane ûux [10] has been the target of many of these investigations. Often the methods that increase the flux of the membranes will decrease the separation performance and vice versa [13].

Taken the above mentioned, a favorable scenary would be the possibility of increasing the membrane flux and retention together [14].

Nanoparticle-blended membranes are a new group of membrane materials that have the beneûts of polymeric membranes and nanostructure materials at the same time $[1,15-17]$. Various nanoparticles have been used in the structure of polymeric membranes. The organic-inorganic membranes, in comparison with the neat membranes, have superior performance.

When nanoparticles are mixed with a polymer solution, the result will be a new material, in terms of morphology and performance; an explanation would be that the intrinsic properties of the nanoparticles are donated to the nanocomposite material.

$\mathrm{TiO}$ [18], Ag [19] and $\mathrm{ZnO}[20,21]$ nanoparticles have an antibacterial property, $\mathrm{ZrO}_{2}$ [22] and Fe [23], [24] have catalytic properties, $\mathrm{SiO}_{2}[25]$ nanoparticles have a nature of electrical conductivity, and $\mathrm{Fe}_{3} \mathrm{O}_{4}$ [26] nanoparticles share a magnetic property to the nanocomposite membrane.

In addition to the importance of choosing the type and concentration of nanoparticles to create membranes with improved properties, another important feature require studying, namely the influence of nanoparticle size on the polymer membranes properties.

Decreasing the nanoparticle size increases its active surface area $\left(\mathrm{m}^{2} / \mathrm{g}\right)$. A higher nanoparticle surface area leads to a higher adsorption of water molecules which gives better hydrophilic property to the membrane surface [27].

Vatanpour et al (2012) studied the influence of the titanium dioxide nanoparticles size with three dimensions of $8 \mathrm{~nm}, 15-25 \mathrm{~nm}, 30 \mathrm{~nm}$ and the surface area, respectively of $300 \mathrm{~m}^{2} / \mathrm{g}, 81 \mathrm{~m}^{2} / \mathrm{g}$ and $50 \mathrm{~m}^{2} / \mathrm{g}$ and showed that the membrane composed of nanoparticles with the smallest size have the largest hydrophilicity due to very high nanoparticle surface area [28].

H.J. Song et al (2014) used in the PSf membranes $\mathrm{SiO}_{2}$ nanoparticles with 4 sizes and demonstrated that the water flux increases with particle size decreasing beceause of the membrane hydrophilicity growth. H.J . Song etal (2014) showed that the influence of the nanoparticle size is also present in the rejection properties of the membrane. The PSf composite membranes containing silica nanoparticles grafted with poly (vinyl alcohol) presents a low solute rejection because of the defects between the nanoparticle aggregates and the polymer. The increasing defects around the silica aggreagates occur with increasing in nanoparticle size [29].

The type, concentration and size of the ZnO nanoparticles are important factors in achieving better efficiency in the membrane fabrication industry.

Blending a small amount of nanoparticles in the polymer casting solution was of interest for this study, despite of the numerous research proof that shows that increasing the nanoparticle amount would increase the flux and hydrophilicity, other studies [28, 30-32] demonstrated that the nanoparticle increment leads to a decrease in flux because of pore blockage caused by excessive nanoparticles leading to pore failure occurred from nanoparticle aggregation. 


\section{Experiemntal part}

Materials and methods

The base polymer is polysulfone (PSf, average Mw 35000), the polymer solvent is 1-methyl-2-pyrrolidone (NMP, $\left.\mathrm{C}_{5} \mathrm{H}_{0} \mathrm{NO}, 99 \%\right)$, all mentioned were supplied from SigmaAldrich. The polyester support layer (Viledon F02471) was supplied from Freudenberg (Winheim, Germany). The ZnO nanoparticles with $<50 \mathrm{~nm}$ particle size were purchased from Sigma-Aldrich and the ZnO nanoparticles with 280.6 $\mathrm{nm}$ average particle size were purchased from Mayam Germany, both nanoparticles were purchased in nanopowder form.

\section{Preparation of mix matrix membranes}

The membranes from this study were obtained by phase inversion, the immersion precipitation method (figure 1[33]). The casting solution was prepared by mixing the PSf polymer ( $25 \mathrm{wt} \%$ ) with the NMP solvent solution at a constant temperature and under continuous stirring. For a homogeneous casting solution, agitation was made for at least 24 hours. The nanoparticle blended membranes were prepared by adding $0.1,0.5$ and $1 \mathrm{wt} \%$ of nanoparticles in the corresponding volume of NMP for $1 \mathrm{~h}$ throught continuous stirring at room temperature. The polymer was then added to the solution and agitation was made for at least $24 \mathrm{~h}$.

After $24 \mathrm{~h}$ the polymer solution was cast with $\sim 250 \mu \mathrm{m}$ thickness using a film applicator (Automatic Film Applicator PA-2101, BYC-Gardner $\mathrm{GmbH}$ ) on very porous nonwoven polyester as support layer. After a limited exposure time to air, the thin film was immersed in a bath of non-solvent (pure water at room temperature). The membranes formed (table 1) were washed and stored in distilled water, until they were used as samples for characterization.

\section{SEM analysis}

The morphology of the samples was investigated using FEI Quanta 200 Scanning Electron Microscope equipped with EDX elemental composition analyzer at an accelerator voltage of $15 \mathrm{kV}$ and $25 \mathrm{kV}$. Nanoparticle samples for SEMEDX observation were prepared by dropping the particle suspension in alcohol onto the SEM stub using carbon adhesive. All samples were coated with gold by sputtering before observation to make them conductive. The presence of zinc oxide nanoparticles with different concentrations were confirmed by EDX spectra.

\section{Contact angle test}

The surface hydrophilicity of the prepared PSf nanocomposite probes was evaluated by measuring the contact angle between the polymer surface and water droplet using a contact angle goniometer (OCA 15EC, DataPhysics). The dropping was repeated for several times and the mean value was reported for the contact angle of each sample.

\section{Porosity}

The membrane porosity was calculated as a function of the membrane weight using the following equation:

$$
\text { Porosity }[\%]=\left(\frac{w_{w}-W_{d}}{V \rho}\right) \times 100
$$

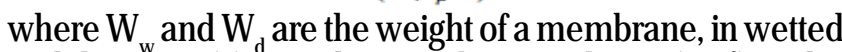
and dry state $(\mathrm{g}) ; \mathrm{V}$ is the membrane volume $\left(\mathrm{cm}^{3}\right)$ and $\rho$ is the density of water $\left(\mathrm{g} / \mathrm{cm}^{3}\right)$. The membranes were immersed in water during $24 \mathrm{~h}$ prior to the measurement of swelling state. The porosity data were the average values obtained for 3 samples of each membrane.

\section{Permeation tests}

The prepared membranes were characterized for water flux and pure water permeability in a dead-end stirred cell (Sterlitech HP4750) with a total volume of $300 \mathrm{~mL}$ and a membrane surface area of $14.6 \mathrm{~cm}^{2}$. The cell fitted with a pressure gauge was pressurized with nitrogen gas to force the liquid through the membrane.

The pure water flux $\left(\mathrm{L} / \mathrm{m}^{2} \mathrm{~h}\right)$ was measured using the gravimetric method and was determined by:

$$
\text { Pure water flux }=\frac{V}{A \cdot t}
$$

where $V$ is the volume of the permeate water $(L), A$ is the effective area of the membrane $\left(\mathrm{m}^{2}\right)$ and $\mathrm{tis}$ the permeation time (h).

Water permeability experiments were carried out with pure water at an operating pressures ranging between 10 and 16 bar at room temperature (aprox. $25^{\circ} \mathrm{C}$ ).

The slope of the linear regression of pure water flux on $\Delta \mathrm{P}$ was determined as the pure water permeability $\left(\mathrm{L} / \mathrm{m}^{2}\right.$ $h$ bar), which was calculated using the following expression:

$$
\text { Pure water permeability }=\frac{\text { purs water flux }}{\Delta p}(3),
$$

where $\Delta \mathrm{p}$ is the operating pressure (bar).

\section{Retention}

The dye of choice is Bromocresol Green (BCG) with a molecular mass of $698.01 \mathrm{~g} / \mathrm{mol}$. The dye concentration is determined spectroscopically using a UV-Vis Spectrophotometer HACH DR 5000 (Hach Lange GmbH, Germany).

The rejection ratio was calculated by the following equation:

$$
\text { Retention }[\%]=\left(1-\frac{c_{f}}{c_{0}}\right) \cdot 100
$$

where $\mathrm{C}_{0}$ represents dye concentrations in feed solution (100 ppm) and $\mathrm{C}_{\mathrm{f}}$ is the permeate concentration.

\begin{tabular}{|c|c|c|c|}
\hline Membrane & $\begin{array}{c}\text { PSf } \\
\text { concentration } \\
{[\mathbf{w t} \%]}\end{array}$ & $\begin{array}{c}\text { NP } \\
\text { concentration } \\
{[\mathbf{w t} \%]}\end{array}$ & $\begin{array}{c}\text { NP size } \\
{[\mathbf{n m}]}\end{array}$ \\
\hline Neat & 25 & - & - \\
\hline $\mathrm{ZnO} 50-0.1$ & 25 & 0.1 & 50 \\
\hline $\mathrm{ZnO} 280-0.1$ & 25 & 0.1 & 280.6 \\
\hline $\mathrm{ZnO} 050-0.5$ & 25 & 0.5 & 50 \\
\hline $\mathrm{ZnO} 280-0.5$ & 25 & 0.5 & 280.6 \\
\hline $\mathrm{ZnO} 50-1$ & 25 & 1 & 50 \\
\hline $\mathrm{ZnO} 280-1$ & 25 & 1 & 280.6 \\
ZnO BLENDED MEMBRANE CHARACTERIZATION BY \\
CONCENTRATIONS AND SIZES \\
Table 1 \\
Mr & & http://www.revmaterialeplastice.ro
\end{tabular}




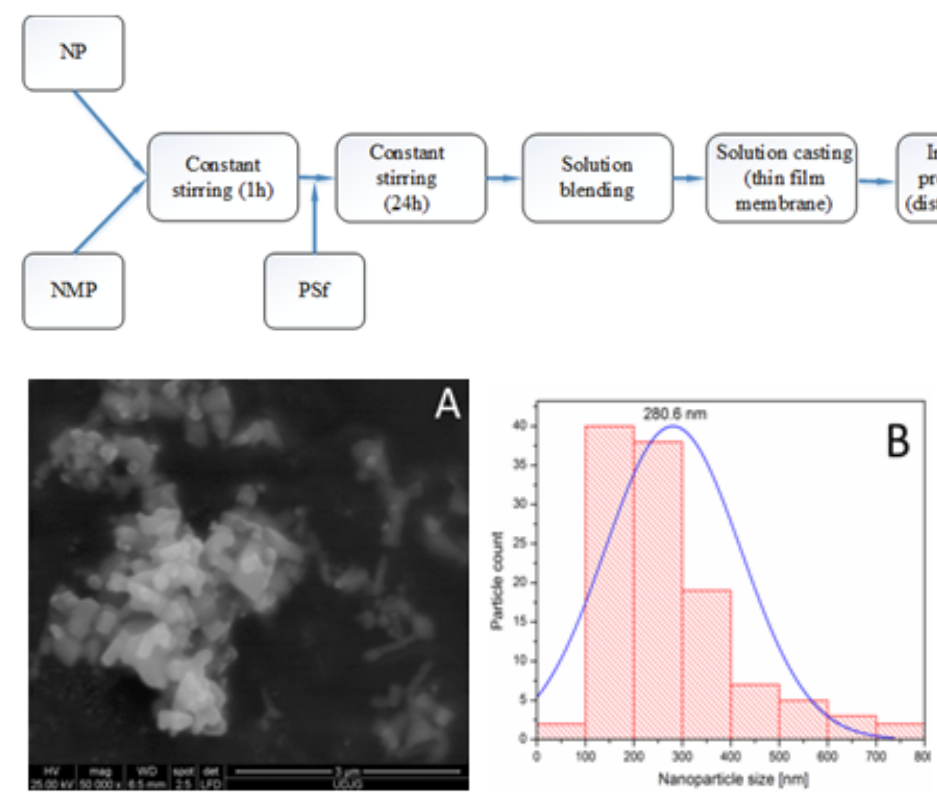

Fig. 2. SEM image of the $\mathrm{ZnO}$ powder (A) and size particle distribution (B)

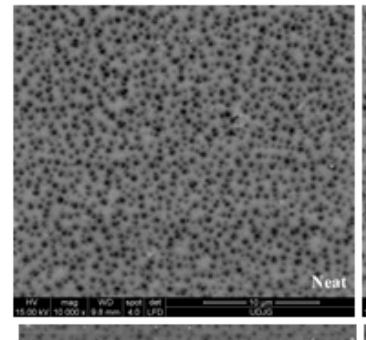

Fig. 1. Scheme showing the preparation method of nanoparticle blended membranes [33]

\section{Results and discussions}

Morphologycal studies

Particle Size Distribution for the Zn0280 nanoparticles

Figure 2 shows SEM image and particle size distribution of nanoparticles measured with a computer image analysis (Image) - open source image analysis software: http:// rsbweb. nih.gov). The average particle size for $\mathrm{ZnO}$ nanoparticle was $280.6 \mathrm{~nm}$.

\section{Membrane characterization with SEM observations}

The membrane surfaces were studied with scanning electron microscopy (SEM). The influence of the sizes and concentrations of the $\mathrm{ZnO}$ nanoparticles are presented in figure 3. In terms of pore density, the surface of PSf neat membrane was compared with the surface of composite membranes. Regarding the pore size, the neat membrane presents larger pores while the composite membranes have smaller pores even when a small concentration of nanoparticles is added in the membrane solution. Consequently, the decrease in pore diameter due to nanoparticle addition is also found in the retention tests of Bromocresol Green. Further increase in nanoparticles causes aggregation both on the surface and just below the top layer of the membrane. Similar results are shown by Balta et al (2012) [21].

Figure 4 presents cross-section SEM images for neat, ZnO50-0.5 and ZnO280-0.5 membranes. The ZnO280-0.5 membranes had the best performance in terms of pure water flux and permeability (fig. 6 and 7). The ZnO-blended membranes (especially Zn050-0.5 membrane) show a thinner skin layer than the neat PSf membrane. The skin layer is the part of the membrane that performs the separation process. By addition of $\mathrm{ZnO}$, the porosity and

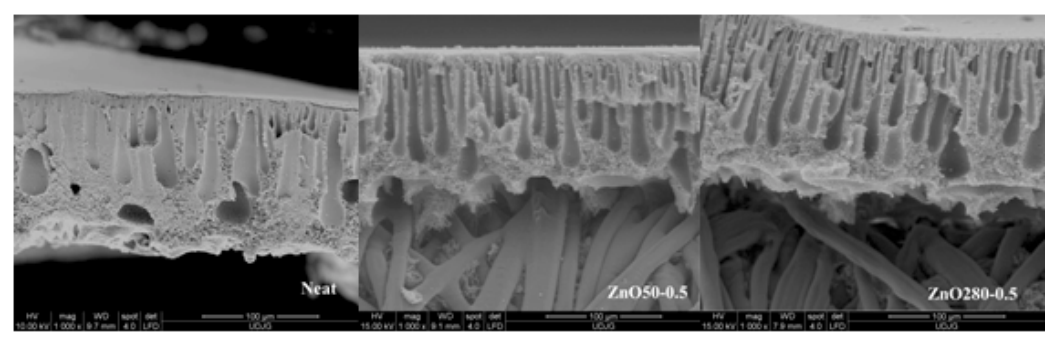

Fig. 4. Cross-sectional SEM images for neat, Zn050-0.5 and ZnO280-0.5 membranes
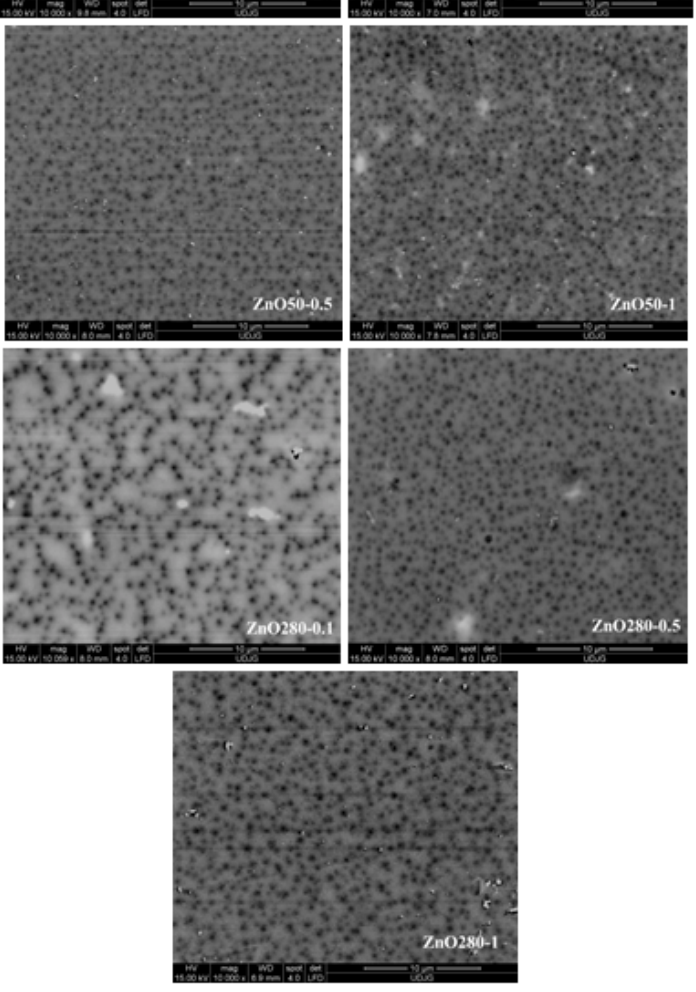

Fig. 3. Top-view SEM images for neat and composite membranes

size of macrovoids was increased [34]. In the case of ZnOblended membranes, solvent-nonsolventexchange is more passive in the presence of nanoparticles during phase inversion process, thus promoting macrovoid formation $[30,35]$. Similar results were observed at different concentrations of nanoparticles [21,31,36]. The SEM images showed that the addition of $\mathrm{ZnO}$ nanoparticles has

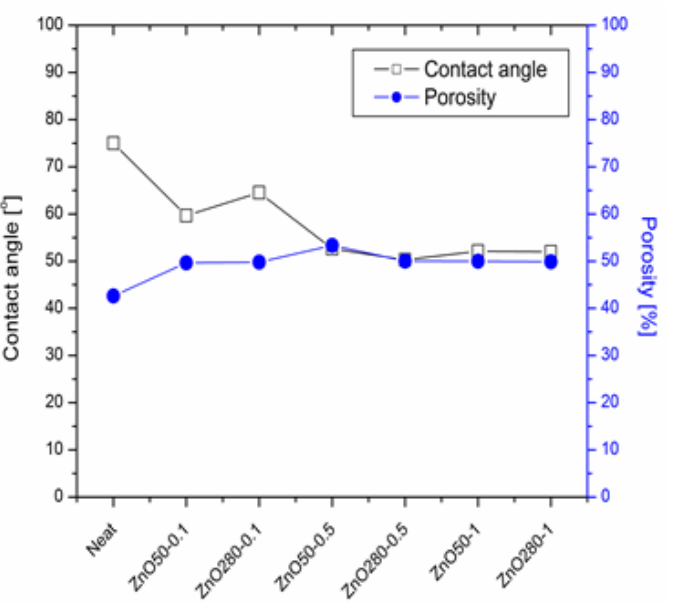

Fig. 5. Contact angle and porosity variation of neat PSf and composite membranes 


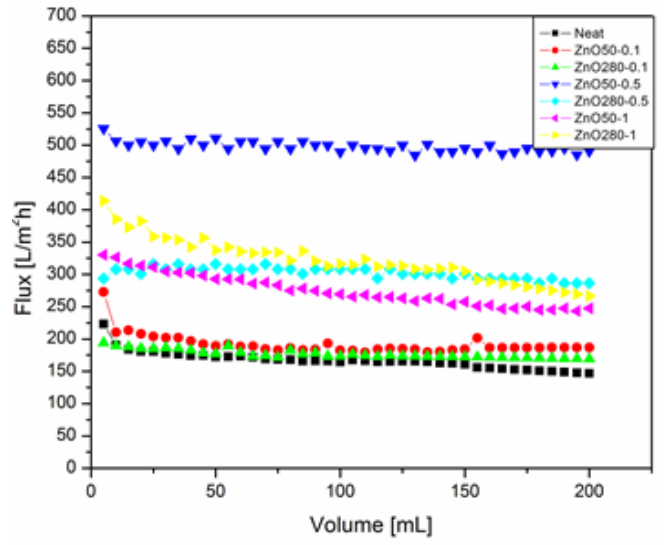

Fig. 6. Influence of nanoparticle size and concentration over pure water flux for neat and nanoparticle-blended membranes

greatly influenced the membrane formation mechanism and the final structure of the membranes.

The elemental examination shown in table 2 and table 3 was done by energy dispersive X-ray (EDX). The results confirm the presence of nanoparticles in the composite membranes, respecting the concentration trend for all of the samples.

\section{Contact angle and porosity}

Figure 5 shows contact angle and porosity measurement for both ZnO nanoparticle sizes and concentrations. The addition of nanoparticles increases the hydrophilicity of membrane due to the hydrophilic property. In theory, increasing nanoparticle concentration in the membrane matrix will decrease the contact angle value. Hydrophilicity did not change significantly when more than 0.5 wt \% nanoparticles were added. The addition of nanoparticles has a positive effect on the membrane hydrophilicity even at very low concentrations. The membranes blended with nanoparticles with size of $50 \mathrm{~nm}$ present a lower contact angle than the $\mathrm{ZnO} 280$ membranes, at all concentrations. Smaller nanoparticles have a higher surface area that leads to a higher adsorption of water molecules which gives better hydrophilic property to the membrane surface [27].

Membrane porosity shows the same tendency as the membrane hydrophilicity. The results for porosity measurements (fig. 5) show that the ZnO-PSf membranes have higher porosity than the neat PSf membrane. Addition of 0.1 and $0.5 \mathrm{wt} \% \mathrm{ZnO}$ nanoparticles leads to porosity increase. Further addition of nanoparticles does not change the porosity.

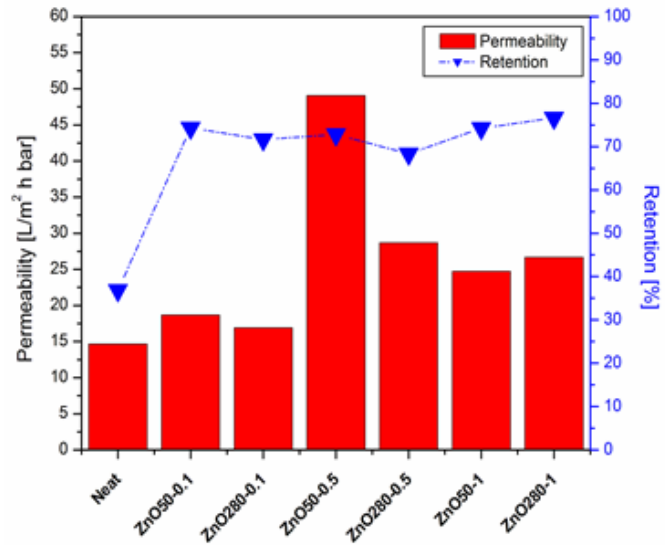

Fig. 7. Pure water permeability and bromocresol retention for neat and composite membranes

Permeation tests

Distilled water flux was determined by timing from 5 to $5 \mathrm{~mL}$ and the values were displayed in figure 6 in order to study the membrane stability. Depending on the size of the nanoparticles in the membrane, it can be seen that the membranes show different variations of the flux.

The first test was with the neat membrane in order to easily see the influence of the nanocomposite membranes (fig. 6). The neat membrane shows an average flux value of $168 \mathrm{~L} / \mathrm{m}^{-2} \mathrm{~h}^{-1}$. The flux value for the membrane $\mathrm{ZnO50}$ 0.1 presents an increase of aprox. $25 \%$ higher than the neat membrane and also a better stability. The membrane ZnO280-0.1 shows the same stability as $\mathrm{ZnO50-0.1.} \mathrm{The}$ flux, however, is slightly lower. Increasing the NP concentration to $0.5 \mathrm{wt} \%$ shows a remarkable increase in flux, $170 \%$ for $\mathrm{ZnO} 280-0.5$ and aproximatly $300 \%$ for

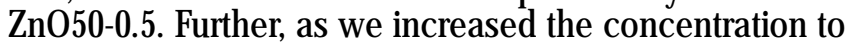
1 wt\%, ZnO50-1 showed a lower value than $\mathrm{ZnO50-0.5}$ and lower stability. Increasing the size of nanoparticles leads to a decrease in flux, so the preferred solution is to introduce in the membrane smaller nanoparticles.

Figure 7 shows the compined effect of pure water permeability and retention of Bromocresol Green. The highest permeability is at a concentration of $0.5 \mathrm{wt} \%$ for both sizes of the nanoparticles, adding a greater amount resulting in a decrease in the permeability for ZnO50-type membranes. The maximum performance the nanoparticles share is with the membrane at $0.5 \mathrm{wt} \% \mathrm{ZnO}$ nanoparticles, higher concentration leading to lower permeability due to nanoparticle aggregation in the polymer matrix.Similar results are also obtained by Liang et al

Table 2

TOP-VIEW EDX ELEMENTAL ANALYSIS (WT\%) OF NEAT AND COMPOSITE MEMBRANES

\begin{tabular}{|c|c|c|c|c|c|c|c|}
\hline Elements & Neat & ZnO50-0.1 & ZnO50-0.5 & ZnO50-1 & ZnO280-0.1 & ZnO280-0.5 & ZnO280-1 \\
\hline $\mathrm{C}$ & 84.08 & 83.51 & 82.58 & 79.60 & 83.21 & 80.33 & 77.89 \\
\hline $\mathrm{O}$ & 8.32 & 9.31 & 9.06 & 8.85 & 9.09 & 8.84 & 10.17 \\
\hline $\mathrm{S}$ & 7.59 & 6.46 & 6.92 & 7.50 & 7.07 & 8.14 & 4.92 \\
\hline $\mathrm{Zn}$ & 0 & 0.72 & 1.44 & 4.04 & 0.63 & 2.69 & 7.03 \\
\hline
\end{tabular}

Table 3

CROSS-SECTION EDX ELEMENTAL ANALYSIS OF NEAT AND COMPOSITE MEMBRANES, EXPRESSED IN WT\%.

\begin{tabular}{|c|c|c|c|c|c|c|c|}
\hline Elements & Neat & ZnO50-0.1 & ZnO50-0.5 & ZnO50-1 & ZnO280-0.1 & ZnO280-0.5 & ZnO280-1 \\
\hline $\mathrm{C}$ & 83.3 & 81.79 & 80.70 & 78.53 & 81.30 & 78.24 & 79.49 \\
\hdashline $\mathrm{O}$ & 8.21 & 10.62 & 10.69 & 11.71 & 10.60 & 9.97 & 9.31 \\
\hline $\mathrm{S}$ & 8.49 & 7.07 & 7.07 & 5.81 & 6.48 & 8.03 & 5.66 \\
\hline $\mathrm{Zn}$ & 0 & 0.52 & 1.54 & 3.95 & 1.63 & 3.76 & 5.55 \\
\hline
\end{tabular}


(2012) [37]. On the other hand, the retention for the blended membranes did not change significantly, meaning that the nanoparticles do not have an influence over the pore size of the membrane, aproved also by top-view SEM images.

Considering the fact that the retention is constant at different concentrations of nanoparticles and the maximum permeability is with membrane $\mathrm{ZnO} 050-0.5$, we conclude that the optimal choice for dye-water treatment is by adding $0.5 \mathrm{wt} \%$ nanoparticles with the size of $50 \mathrm{~nm}$.

\section{Conclusions}

The result of the present research work show that $\mathrm{ZnO}$ nanoparticles have a positive influence on the PSf membranes, even at low concentration. In order to choose the optimal composite membrane for water treatment, both nanoparticles size and concentration need to be taken in consideration. The membrane embedded with ZnO nanoparticle with the size of $50 \mathrm{~nm}$ and concentration of $0.5 w t \%$ exhibits the best properties in terms of flux stability, porosity, contact angle, permeability and retention. All of the other membranes excels at a specific property, but

The results showed that adding a quantity of $0.5 \mathrm{wt} \%$ increase the properties of membranes in terms of flux stability, porosity, contactangle, permeability and retention. Exceeding this concentration leads to performance decreasing. Also, the membrane with $0.5 \mathrm{wt} \%$ and $50 \mathrm{~nm}$ nanoparticle size show the highest performance in comparison with $280.6 \mathrm{~nm}$ particle size diameter.

\section{References}

1. GUO, W., H. NGO, H., LI, J., Bioresour. Technol., vol. 122, 2012, p. 27-34.

2. SHIRAZI, M. J. A., BAZGIR, S., SHIRAZI, M. M. A., RAMAKRISHNA, S., Desalin. Water Treat., vol. 51, nr. 31-33, 2013, p. 5974-5986.

3. NECHIFOR, G., PASCU, E.D., NEAGU, M.P., PANAIT, V. I. F., UPB Sci. Bull. Ser. B Chem. Mater. Sci., vol. 75, no. 4, 2013, pp. 191-198.

4. SHIRAZI, M. M. A., KARGARI, A., TABATABAEI, M., ISMAIL, A. F., MATSUURA, T., Chem. Eng. Process. Process Intensif., vol. 78, 2014,p. 58-66.

5. NEAGU, E., ROMAN, G. P., RADU, G. L., NECHIFOR, G., Rom. Biotechnol. Lett., vol. 15, no. 1, 2010, p. 5042-5048.

6. SIMIONESCU, S., TEODORESCU, S., ION, R. M., VOICILA, E., NECHIFOR, G., Mat. Plast., 54, no. 1, 2017, p. 14

7. BAKER, R.W., Membrane Technology and Applications, 2nd ed. Menlo Park, California: John Wiley and Sons, 2004.

8. GHIMPUSAN, M.P.P., NECHIFOR, G, DIN,I.S., NECHIFOR, A.C., Mat.

Plast., 53, no. 4, 2016, p. 578

9. HAUSMANNS, B. K. S., LAUfENBERG, G., J. Membr. Sci., vol. 104, no. (1-2),1996, p. 95-98.

10.CATH, A.E.C.T.Y., ADAMS, V.D., J. Membr. Sci., vol. 228, no. 1, 2004, p. 5-16.

11.ALEXANDRINA, I., KATALIN, T. S., OCTAVIAN, D., VALERIU, D., SERGIU, S., GHEORGHE, N., UPB Sci. Bull. Ser. B Chem. Mater. Sci., vol. 75 , no. 3, 2013, p. 53-64.
12.MANEA, L. R., CRAMARIUC, B., POPESCU, V., CRAMARIUC, R., SANDU, I., CRAMARIUC, O., Mat. Plast., 52, no. 1, 2015, p. 82

13.EMADZADEH, D., LAU, W. J., ISMAIL, A. F., Desalination, vol. 330, 2013, p. 90-99.

14.CHEN, X. N., WAN, L. S., WU, Q. Y., ZHI, S. H., XU, Z. K., J. Memb. Sci., vol. 441, 2013, p. 112-119.

15.NG, L. Y., MOHAMMAD, A. W., LEO, C. P., HILAL, N., Desalination, vol. 308, 2013,p. 15-33.

16.KIM, J., VAN DER BRUGGEN, B., Environ. Pollut., vol. 158, no. 7, 2010, p. 2335-2349.

17.RADU, A.-L. et al., Mat. Plast., 47, no. 2, 2010, p. 167

18.YANG, H. L., TE LIN, J. C., HUANG, C., Water Res., vol. 43, no. 15, 2009, p. 3777-3786.

19.ZODROW, K. et al., Water Res., vol. 43, no. 3, 2009, pp. 715-723.

20.LI, L. H., DENG, J. C., DENG, H. R., LIU, Z. L., XIN, L., Carbohydr. Res., vol. 345, no. 8, 2010, p. 994-998.

21.BALTA, S., SOTTO, A., LUIS, P., BENEA, L., VAN DER BRUGGEN, B., KIM, J., J. Memb. Sci., vol. 389, 2012, p. 155-161.

22.MAXIMOUS, N., NAKHLA, G., WAN, W., WONG, K., J. Memb. Sci., vol. 352, no. 1-2, 2010, p. 222-230.

23.XU, D. B. J., Ind. Eng. Chem. Res., vol. 46, 2007, p. 2348-2359.

24.PANAITESCU, C., BOMBOS, M., JUGANARU, T., VASILIEVICI, G., VARTIRES, A., Mat. Plast., 53, no. 2, 2016, p. 211

25.YU, S., ZUO, X., BAO, R., XU, X., WANG, J ., XU, J ., Polymer (Guildf)., vol. 50, no. 2, 2009, p. 553-559.

26.HOMAYOONFAL, A. F. I. M., MEHRNIA, M.R., SHARIATY-NIASSAR, M., AKBARI, A., SARRAFZADEH, M.H., DESALIN. Water Treat., 2014, p. $1-7$.

27.KALLIO, T. et al., Colloids Surfaces A Physicochem. Eng. Asp., vol. 291, no. 1-3, 2006, pp. 162-176.

28.VATANPOUR, V., MADAENI, S. S., KHATAEE, A. R., SALEHI, E., ZINADINI, S., MONFARED, H. A., Desalination, vol. 292, 2012, p. 19-29. 29.SONG, H. J., JO, Y. J., KIM, S. Y., LEE, J., KIM, C. K., J. Memb. Sci., vol. 466, 2014, p. 173-182.

30.RAHIMPOUR, A., MADAENI, S. S., TAHERI, A. H., MANSOURPANAH, Y., J. Memb. Sci., vol. 313, no. 1-2, 2008, p. 158-169.

31.LI, J. F., XU, Z. L., YANG, H., YU, L. Y., LIU, M., Appl. Surf. Sci., vol. 255, no. 9, 2009, p. 4725-4732.

32.WU, G., GAN, S., CUI, L., XU, Y., Appl. Surf. Sci., vol. 254, no. 21, 2008, p. 7080-7086.

33.ARTHANAREESWARAN, G., SRIYAMUNA DEVI, T. K., RAAJENTHIREN, M., Sep. Purif. Technol., vol. 64, no. 1, 2008, p. 38-47.

34.BURUIANA, D., TIRON, L.G., PINTILIE, S.C., SIOMIONESCU, C.L., BALTA, S., Rev. Romana Mater. / Rom. J. Mater., vol. 45, no. 4, 2015, p. 354-357.

35.LUO, M. L., ZHAO, J. Q., TANG, W., PU, C. S., Appl. Surf. Sci., vol. 249, no. 1-4, 2005, p. 76-84.

36.DAMODAR, R. A., YOU, S. J., CHOU, H. H., J. HAZARD. Mater., vol. 172, no. 2-3, 2009, p. 1321-1328.

37.LIANG, S., XIAO, K., MO, Y., HUANG, X., J. Memb. Sci., vol. 394-395, 2012, p. 184-192.

$\overline{\text { Manuscript received: } 28.12 .2016}$ 